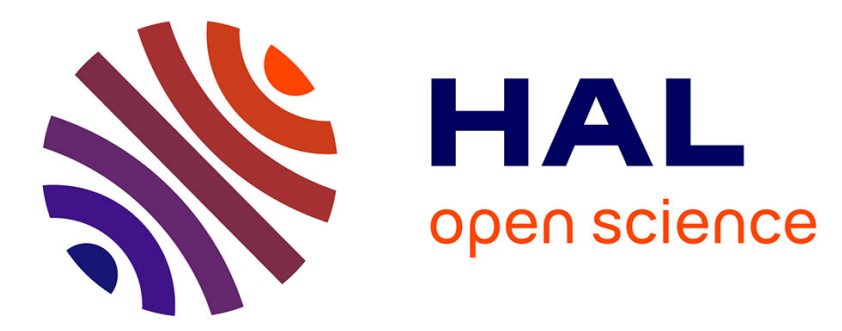

\title{
Dual targeting of Src and ER prevents acquired antihormone resistance in breast cancer cells
}

S. Hiscox, N. J. Jordan, C. Smith, M. James, L. Morgan, K. M. Taylor, T. P. Green, R. I. Nicholson

\section{- To cite this version:}

S. Hiscox, N. J. Jordan, C. Smith, M. James, L. Morgan, et al.. Dual targeting of Src and ER prevents acquired antihormone resistance in breast cancer cells. Breast Cancer Research and Treatment, 2008, 115 (1), pp.57-67. 10.1007/s10549-008-0058-6 . hal-00478230

\section{HAL Id: hal-00478230 \\ https://hal.science/hal-00478230}

Submitted on 30 Apr 2010

HAL is a multi-disciplinary open access archive for the deposit and dissemination of scientific research documents, whether they are published or not. The documents may come from teaching and research institutions in France or abroad, or from public or private research centers.
L'archive ouverte pluridisciplinaire HAL, est destinée au dépôt et à la diffusion de documents scientifiques de niveau recherche, publiés ou non, émanant des établissements d'enseignement et de recherche français ou étrangers, des laboratoires publics ou privés. 


\title{
Dual targeting of Src and ER prevents acquired antihormone resistance in breast cancer cells
}

\author{
S. Hiscox $\cdot$ N. J. Jordan · C. Smith $\cdot$ M. James • \\ L. Morgan · K. M. Taylor · T. P. Green · \\ R. I. Nicholson
}

Received: 5 February 2008/Accepted: 7 May 2008/Published online: 21 May 2008

(C) Springer Science+Business Media, LLC. 2008

\begin{abstract}
Acquired resistance to endocrine therapies presents a major obstacle to the successful treatment of breast cancer patients. Previously, we have shown that acquisition of resistance to tamoxifen in breast cancer cells is accompanied by an elevation in Src kinase activity which promotes an aggressive, invasive phenotype in vitro. Here, we have explored the potential therapeutic effects of combining Src inhibition with anti-oestrogen treatment on the development of endocrine insensitivity in breast cancer cells. Treatment of MCF7 and T47D cells with tamoxifen alone resulted in an initial growth inhibitory phase followed by the eventual development of tamoxifen resistance together with an elevation of Src kinase activity, which was central to their increased invasive capacity. Chronic exposure of both cell types to the Src inhibitor, AZD0530, as a monotherapy resulted in outgrowth of AZD0530-resistant cells, in which Src kinase activity remained suppressed as did their in vitro invasive nature. Treatment of both MCF7 and T47D cells with AZD0530 in combination with tamoxifen resulted in a reduction of Src activity together with inhibition of focal adhesion kinase phosphorylation and a complete abrogation of their in vitro invasive behaviour. Furthermore, combination therapy significantly suppressed expression of cyclinD1 and c-myc and prevented cell proliferation and the subsequent emergence of a resistant phenotype, with total cell loss occurring by 12
\end{abstract}

S. Hiscox $(\bowtie) \cdot$ N. J. Jordan · C. Smith · M. James - L. Morgan ·

K. M. Taylor · R. I. Nicholson

Tenovus Centre for Cancer Research, Welsh School of

Pharmacy, Redwood Building, King Edward VII Avenue,

Cardiff, Wales CF10 3XF, UK

e-mail: hiscoxse1@cf.ac.uk

T. P. Green

AstraZeneca, Alderley Park, Macclesfield, UK weeks. These data demonstrate that pharmacological targeting of Src kinase, in conjunction with antihormone therapies, effectively prevents antihormone resistance in breast cancer cells in vitro and suggests a potential novel therapeutic benefit of Src kinase inhibitors clinically.

Keywords Src $\cdot$ ER - Tamoxifen-resistance .

Breast cancer

\section{Introduction}

Steroid hormones are central in directing the growth and development of oestrogen receptor (ER) positive breast cancers; as such, endocrine therapies which seek to perturb the steroid hormone environment of the tumour cells can promote extensive remissions in established disease and provide significant benefits in terms of patient survival $[1,2]$. However, despite the undoubted improvements brought by endocrine therapies, in practice their benefits are limited by the capacity of a significant proportion of breast cancer patients that show an initial positive response to ultimately suffer a recurrence due to acquired antioestrogen resistance [3-6]. In these patients, relapse on such therapies clinically presents as local and/or regional recurrences, frequently with distant metastases [7] and the outlook for these patients is poor. Recent in vitro studies have demonstrated that chronic exposure of breast cancer cells to tamoxifen ultimately results in the acquisition of tamoxifen resistance $[8,9]$ which is accompanied by the gain of aggressive, invasive characteristics [10, 11].

Overexpression of the non-receptor tyrosine kinase, Src, and/or an increase in its kinase activity has been associated with the development and progression of a number of human malignancies including breast cancer $[12,13]$ where 
it has been implicated in metastatic progression [14]. Interestingly, it has recently been reported that expression of activated Src is associated with a reduced recurrencefree survival in ductal carcinoma in situ [15]. Steroidinduced cellular responses involve activation of Src and, although the molecular pathways involved in these responses have yet to be fully defined, can involve growth factor receptor signalling. For example, targeting of the Cterminal region of the ER to the membrane of ER-negative breast cancer cells results in oestrogen-stimulated, c-Srcdependent responses including activation of the epidermal growth factor receptor (EGFR) [16]. Furthermore, oestrogen stimulation results in the recruitment and activation of Src leading to activation of Shc, MEK/MAPK, and PI3K/ PKB [17]. Significantly, we have recently identified that Src kinase activity is significantly elevated in tamoxifenresistant breast cancer cells, where it promotes an aggressive, invasive phenotype [11]. A role for Src kinase in acquired endocrine resistance has also been suggested by others, where it may contribute to cellular growth via regulation of Cas-mediated EGFR signalling [18] or through interplay with focal adhesion kinase (FAK) [19].

Given the putative role of $\mathrm{Src}$ in acquired tamoxifen resistance, we hypothesised that targeting of Src alongside the ER would present a novel strategy to suppress the development of an aggressive endocrine-resistant phenotype. In this report, we demonstrate that combined targeting of the ER and Src kinase using tamoxifen and the novel Src inhibitor, AZD0530 [20] in two separate, ERpositive breast cancer cell lines, greatly enhances the growth inhibitory effects seen with either agent alone, preventing the development of acquired tamoxifen resistance.

\section{Materials and methods}

\section{Cell culture}

Tamoxifen-responsive MCF7 and T47D breast cancer cells were routinely cultured in home medium (RPMI medium supplemented with 5\% foetal calf serum (FCS), $10 \mathrm{IU} / \mathrm{ml}$ penicillin, $10 \mu \mathrm{g} / \mathrm{ml}$ streptomycin, $2.5 \mu \mathrm{g} / \mathrm{ml}$ fungizone and $200 \mathrm{mM}$ glutamine). Subsequent treatment of these cells was performed in experimental medium (phenol-red free RPMI containing 5\% charcoal-stripped, steroid-depleted FCS with antibiotics and glutamine as above) supplemented with $10^{-7} \mathrm{M}$ tamoxifen (4-hydroxy tamoxifen), AZD0530 $(0-1 \mu \mathrm{M})$ or both agents in combination as indicated. In all cases the tissue culture medium ( \pm tamoxifen/AZD0530) was replaced every 3 days unless otherwise stated. Stock solutions of AZD0530 and tamoxifen were dissolved in DMSO and ethanol respectively prior to diluting in tissue culture medium. Corresponding DMSO/ethanol controls had no effect on the parameters analysed. Treatment of cells with AZD0530 alone produced similar results irrespective of whether cells were cultured in home medium or experimental medium.

\section{Cell growth assays}

Cells were grown for 10 days in the presence of tamoxifen $\left(10^{-7} \mathrm{M}\right)$, AZD0530 $(0-1 \mu \mathrm{M})$ or a combination of both agents. Changes in cell growth were then evaluated by means of trypsin dispersion and subsequent counting using a Coulter Counter. To determine the effects of chronic exposure to these agents on the growth of both cell lines, log-phase cell cultures were either grown in home medium with no treatments or exposed to tamoxifen \pm AZD0530 $(0-1 \mu \mathrm{M})$ in experimental medium with routine passaging once cell confluency had reached $\sim 80 \%$. Each passage was subsequently recorded and plotted against time in culture to allow the comparison of the ability of these treatments to maintain their growth suppressive effects.

\section{Measurement of apoptosis}

Cells were harvested at various times during long-term culture and apoptotic events analysed using a Vybrant Apoptosis Assay (Molecular Probes, Eugene, OR, USA) as follows: harvested cells were washed and resuspended to $1 \times 10^{6}$ cells $/ \mathrm{ml}$ in PBS prior to the addition of FITClabelled YO-PRO-1 (final concentration of $100 \mathrm{nM}$ ) and TRITC-labelled propidium iodide (final concentration of $1.5 \mathrm{nM}$ ) for $30 \mathrm{~min}$ at $4^{\circ} \mathrm{C}$. Cells were immediately read on a FACScan flow cytometer. Negative controls consisted of cells alone without antibody. The mean fluorescence of a minimum of $1 \times 10^{4}$ cells was determined for each sample and the experiments were repeated 4 times, each time in duplicate. Data represents mean of three separate experiments, each performed in duplicate.

\section{RT-PCR}

Total RNA was extracted from MCF7 and T47D cells using Trizol reagent (Life Technologies) and converted to cDNA using random hexamers and Super-Script II reverse transcriptase (Invitrogen). cDNA was amplified using PCR primer pairs (MWG Biotech) specific for c-myc (Fwd:5'ccaagctcgtctcagagaag- $3^{\prime}$, Rev:5'-cagcaggatagtccttccga- $3^{\prime}$ ) and cyclin-D1 (Fwd:5'-ggatgctggaggtctgcgag-3', Rev:5' gagaggaagcgtgtgaggcg- $3^{\prime}$ ). All PCR reactions were performed as multiplex reactions with PCR primers specific for $\beta$-actin (Fwd:5'-ccttcctgggcatggagtcct- $3^{\prime}$, Rev:5'-ggag caatgatcttgatctt- $3^{\prime}$ ) as an internal control. PCR was performed in a semi-quantitative manner using 25 cycles so 
that products were in the linear range of amplification. PCR products were separated on a $1.0 \%$ agarose gel, stained with ethidium bromide and visualized and photographed under ultraviolet light.

\section{Measurement of cellular proliferation}

Ki67 antigen was assessed in both cell types following treatment with tamoxifen \pm AZD0530 using the MIB-1 anti-Ki67 antibody (Coulter Electronics, Luton, United Kingdom). Briefly, cells were grown and treated in petri dishes containing coverslips as indicated then washed and fixed in formal saline. Primary antibody (MIB-1) was applied to the coverslips after blocking with PBS/Tween and incubation performed for $60 \mathrm{~min}$. After washing in PBS, the secondary antibody (Mouse Envision, DAKO UK Ltd., Ely, Cambridgeshire) was applied to the coverslips for $75 \mathrm{~min}$. After further PBS washing, the chromogen ("SigmaFast" DAB, Sigma, Poole, UK) was added to the cells for $10 \mathrm{~min}$ after which the coverslips were rinsed in distilled water. Samples were counterstained with $20 \%$ haematoxylin for 3 min and mounted for examination by light microscopy. Control coverslips (no primary antibody) were checked for non-specific binding before assessing staining intensity in the test samples. The percentage of Ki67-positive cells was estimated after counting at least 1,000 tumour cells.

\section{Cell cycle analysis}

Cells were cultured in the presence or absence of tamoxifen, AZD0530 or the combination for up to 8 weeks. For analysis of cell cycle, the cells were harvested by trypsinisation and resuspended at $10^{-7}$ cells/ml before using the Cycletest Plus DNA reagent kit (Becton Dickinson) following the manufacturers instructions to produce uniform suspensions of single nuclei with DNA stained and suitable for reading on a FACScan Flow Cytometer (Becton Dickinson).

\section{Cell migration and invasion assays}

Cells were exposed to tamoxifen \pm AZD0530 for the times indicated in the figures prior to seeding onto fibronectincoated polycarbonate, microporous membranes $(8 \mu \mathrm{m}$ pore size) at $5 \times 10^{4}$ cells/membrane and allowed to migrate to the underside of the membrane for a period of $24 \mathrm{~h}$. Migratory cells were fixed, stained with $0.5 \%$ crystal violet and counted. To determine the cells' invasive capacity, cells were seeded onto Matrigel-coated, porous membranes as described previously [10]. After $72 \mathrm{~h}$ culture, invaded cells were fixed, stained with DAPI and counted. Cell migration/invasion was quantified as the mean number of cells observed in each of eight random fields of view per sample, in duplicate with each experiment performed a minimum of three times.

\section{Western blotting}

Cells were harvested at 2 week intervals during their exposure to tamoxifen \pm AZD0530 and lysates resolved by SDS-PAGE using $8 \%$ gels. Proteins were immobilised on nitrocellulose membranes and subsequently probed with phospho-specific antibodies that recognised the active forms of Src (Y419) and FAK (Y861, both from Biosource, Nivelles, Belgium). Tyrosine 419 in Sre is a major positive-regulatory site, the phosphorylation of which increases Src activity and is widely used as a indicator of changes in Src activity both in vitro and in vivo (for example, see [21]. Although other tyrosine residues on FAK are phosphorylated in a Src-dependent manner, phosphorylation of FAK at Y861 was investigated as this is well known to regulate cancer cell migration and to be increased in metastatic breast cancer cells $[22,23]$ and thus may be important in regulating the effects of Src kinase in cancer cells. Repeat immunoprobings were performed using pan antibodies to determine total levels of these proteins and with $\beta$-actin to correct for loading. Western blots were then scanned to provide data for quantitation, with normalization against actin first. Each experiment was performed at least three times with representative gels shown.

\section{Statistical analysis}

Data was analysed using one-way ANOVA with post-hoc analysis in order to examine whether inclusion of AZD0530 $(0.1$ and $1 \mu \mathrm{M})$ significantly affected the observations obtained with tamoxifen alone. Significance was assumed at $P<0.05$.

\section{Results}

AZD0530 and tamoxifen together showed improved growth inhibitory effects compared with either agent alone

Treatment of both MCF7 and T47D cells with AZD0530 resulted in a dose-dependent inhibition of Src kinase activity, as shown by a decrease in phosphorylation of Src at Y419 (Fig. 1a) whilst having no effect on the level of Src protein in these cells. Despite both cell type having similar levels of Src kinase, T47D cells exhibited a small but nonsignificant decrease in sensitivity to the Src inhibitor. However, at the highest concentration of AZD0530 $(1 \mu \mathrm{M})$, 
Fig. 1 Western blotting analysis demonstrated that AZD0530 inhibited Src kinase phosphorylation at Y419 in both MCF7 and T47D cells in a dosedependent manner whilst MAPK activity was inhibited at only $1 \mu \mathrm{M}$ (a). MCF7 and T47D cell growth in response to increasing concentrations of AZD0530 (b) or tamoxifen \pm AZD0530 (c) over 10 days was quantified using a Coulter counter. Whereas both AZD0530 and tamoxifen alone inhibited cellular growth in a dose-dependent manner, AZD0530, when combined with tamoxifen, dramatically reduced cellular growth over this time point. $\dagger P<0.02$ vs. control; $* P<0.02$ vs. tamoxifen alone at this data point. Data are means of at least three independent experiments
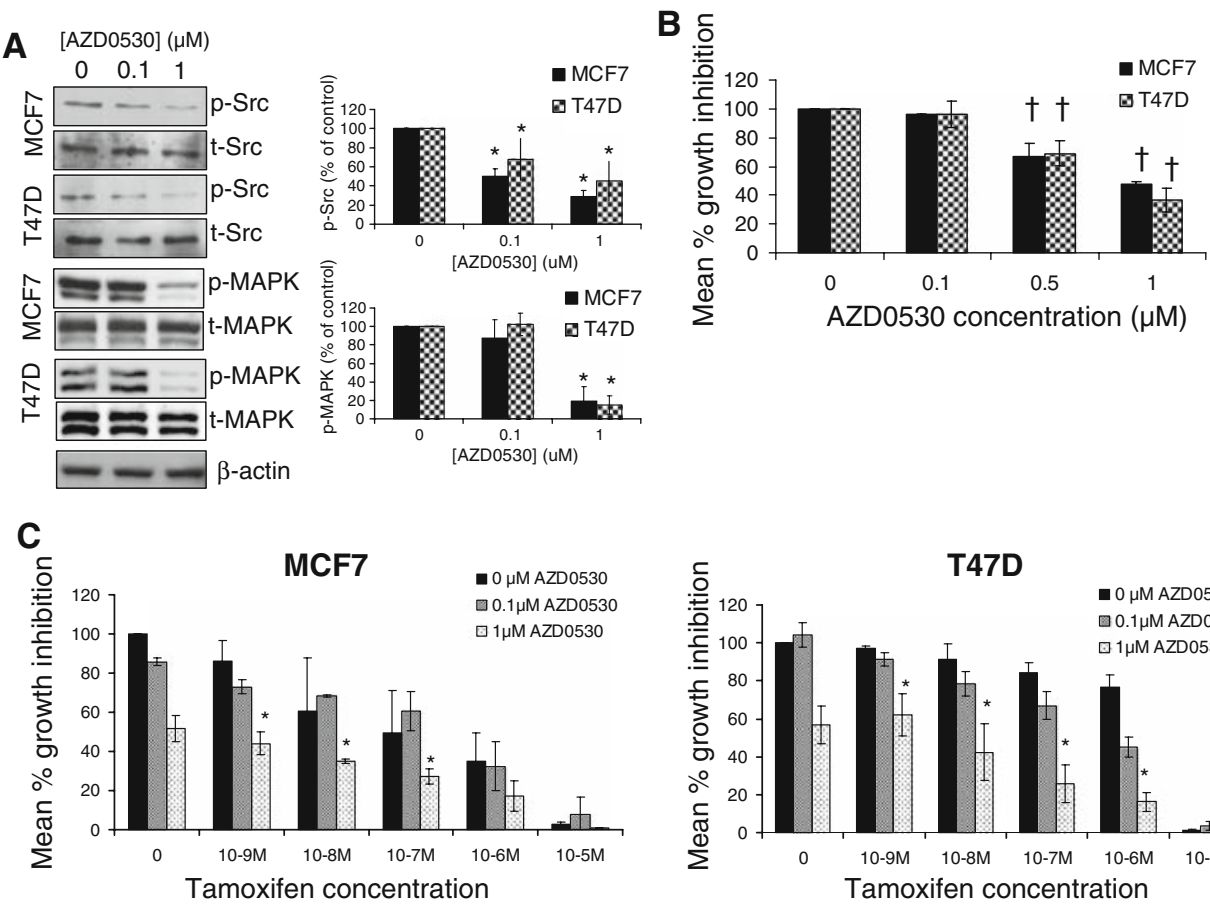

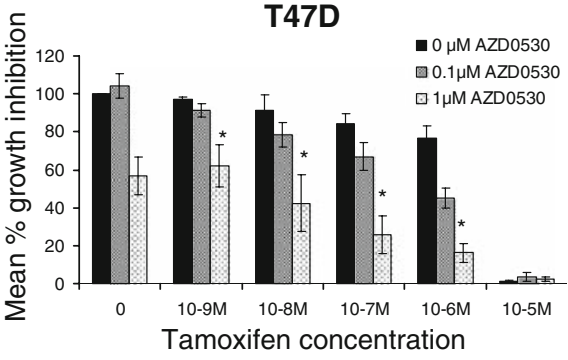

a corresponding inhibition of MAPK activity was also observed in both cell types. Treatment of cells with AZD0530 also resulted in a dose-dependent decrease in growth over a period of 10 days (Fig. 1b). A modest suppression of cell growth was seen following culture with tamoxifen alone at this time point (Fig. 1c) with T47D cells appearing more resistant to its growth inhibitory effects, as has been previously reported [24]. Importantly, when AZD0530 $(1 \mu \mathrm{M})$ and tamoxifen were combined, maximal inhibition of cell growth over this time period was observed (Fig. 1c). Analysis of the growth data by isobologram suggested that the combined effect of the two drugs was additive rather than synergistic (data not shown).

AZD0530 and tamoxifen prevent the emergence of tamoxifen resistance

Since prolonged exposure of breast cancer cell lines to antioestrogens ultimately results in acquired resistance $[8,9]$, a process in which activated Src has been implicated [11, 18, 19], we wished to determine whether inhibition of Src activity alongside tamoxifen treatment would delay or prevent the development of resistance. Chronic exposure of both MCF7 and T47D cells to tamoxifen resulted in the emergence of a resistant phenotype after an initial period of growth suppression, as demonstrated by the ability of these cells to regain their ability to grow in the presence of the antihormone (Fig. 2). Interestingly, treatment with AZD0530 as a monotherapy also ultimately resulted in cells which were able to grow in the presence of this inhibitor, suggestive of further acquired drug resistance. Significantly, our data revealed that cells exposed to the combination of tamoxifen and AZD0530 did not grow but rather, a gradual loss of cells in culture was observed, with no viable cells visible by approximately 13 weeks (Fig. 2).

Addition of AZD0530 to tamoxifen does not enhance apoptosis

We next investigated whether tamoxifen and AZD0530 combined increased cellular apoptosis. FACS analysis of cells cultured in the presence of tamoxifen \pm AZD0530 revealed that combining these agents did not significantly increase the extent of apoptosis seen with either compound as a single agent. (Table 1 shows data from 1 and 8 weeks' continuous culture in the presence of these agents).

AZD0530 and tamoxifen in combination significantly suppress expression of the Ki67 antigen

Since an induction of apoptosis did not appear to play a significant role in AZD0530-induced prevention of acquired tamoxifen resistance, we next evaluated the proliferative capacity of MCF7 and T47D cells cultured in the presence of tamoxifen with and without AZD0530. Analysis of the Ki67 expression, a marker of cellular proliferation, revealed that the combination of AZD0530 and tamoxifen significantly inhibited cellular proliferation in both cell lines, an effect observable as early as 10 days post treatment (Fig. 3a-MCF7 cells, 3b-T47D cells). 
Fig. 2 MCF7 and T47D cells were exposed to tamoxifen \pm AZD0530 $(1 \mu \mathrm{M})$ with routine passageing as required or until all cells were dead. Graphs are representative of four separate long-term experiments. The number of weeks taken for the cells to acquired resistance, as demonstrated by a regain in their growth in the presence of inhibitor, was recorded for both cell types for each experiment and presented in the accompanying table
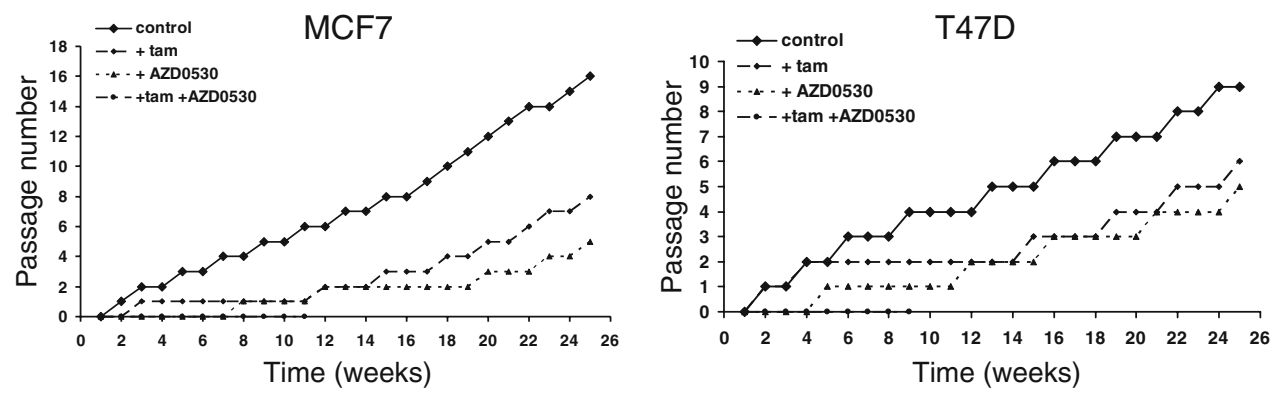

\begin{tabular}{|c|c|c|c|c|c|}
\hline & & Control & + tam & $\begin{array}{c}+ \text { AZD0530 } \\
(1 \mu \mathrm{M})\end{array}$ & $\begin{array}{c}+ \text { tam +AZD0530 } \\
(1 \mu \mathrm{M})\end{array}$ \\
\hline \multirow{2}{*}{$\begin{array}{l}\text { Mean time } \\
\text { to } \\
\text { resistance } \\
\text { (wks) }\end{array}$} & MCF7 & - & $13 \pm 4$ & $16 \pm 3$ & \multirow{2}{*}{$\begin{array}{c}\text { No resistance } \\
\text { developed; all } \\
\text { cells dead by } \\
\text { week } 13 \pm 3\end{array}$} \\
\hline & T47D & - & $17 \pm 4$ & $12 \pm 5$ & \\
\hline
\end{tabular}

Table 1 The extent of apoptosis in cell populations treated with tamoxifen ('Tam' $\left.10^{-7} \mathrm{M}\right) \pm$ AZD0530 $(1 \mu \mathrm{M})$ over $1-8$ weeks was determined using FACS analysis

\begin{tabular}{lll}
\hline & \multicolumn{2}{l}{ Mean fold change in apoptotic cells (vs. control) } \\
\cline { 2 - 3 } & Wk1 & Wk8 \\
\hline MCF7 & \\
Control & 1 & 1 \\
Tam & $0.57 \pm 0.23$ & $1.71 \pm 0.19$ \\
AZD & $1.60 \pm 0.40$ & $1.54 \pm 0.60$ \\
Tam \pm AZD & $0.45 \pm 0.15$ & $1.96 \pm 0.98$ \\
T47D & & \\
Control & 1 & 1 \\
Tam & $1.29 \pm 0.09$ & $2.05 \pm 0.19$ \\
AZD & $1.10 \pm 0.12$ & $2.95 \pm 0.05$ \\
Tam \pm AZD & $1.27 \pm 0.05$ & $1.84 \pm 0.80$ \\
\hline
\end{tabular}

Data is presented as mean fold change in apoptotic cells $( \pm$ sd) vs. untreated control. Treatment with AZD0530 and tamoxifen combined did not significantly alter the level of apoptosis seen with tamoxifen as a single agent

AZD0530 and tamoxifen together inhibit expression of key growth-regulatory genes

To address possible mechanisms underlying these proliferation changes, we analysed the expression of a number of cell proliferation regulators which may be modulated in a Src-dependent manner. In agreement with recent reports showing inhibition of key cell cycle control elements following Src inhibition [25], we observed that suppression of Src activity in both MCF7 and T47D cells resulted in reduced expression of both cyclin-D1, necessary for the progression of cells from $\mathrm{G} 1$ to $\mathrm{S}$ phase, and c-Myc, a positive regulator of cellular proliferation [26] (Table 2). Moreover, cells treated with the combination of the two agents had significantly lower levels of these genes at times $>4$ weeks (Table 2).

Subsequent analysis of cell cycle progression in cells after 4 weeks treatment revealed that the combination of tamoxifen and AZD0530 together significantly reduced the number cells in $\mathrm{S}$ phase cell cycle in both cell lines compared with either treatment alone (Fig. 4).

AZD0530 and tamoxifen together show improved effects against migration and invasion compared with either agent alone

We have previously reported that chronic exposure to tamoxifen results in the acquisition of a highly migratory and invasive phenotype in vitro in which Src activation plays a key role $[10,11]$. We thus wished to determine whether inclusion of AZD0530 with tamoxifen during these long-term treatments could prevent this. The migratory and invasive capacity of both MCF7 and T47D cells was assessed every 2 weeks during long-term culture with tamoxifen \pm AZD0530. After 10 weeks, the migratory and invasive capacity of MCF7 cells was seen to increase over their basal level (Fig. 5a); interestingly, analysis of lysates obtained from such cells revealed that levels of Src kinase were also elevated at this time point as was the activity of FAK, a Src-associated substrate involved in cellular migration [27] (Fig. 5b). The migratory and invasive capacity of T47D cells at this time point was again elevated following culture with tamoxifen alone, although these levels did not reach significance until $\geq 12$ weeks, at which time cells demonstrated greatly increased Src and FAK activity (Fig. 5b). Inclusion of AZD0530 with tamoxifen significantly suppressed cell migration and invasion at all time points (Fig. 5a), and consistently inhibited the activity of Src and FAK (Fig. 5b). 
Fig. 3 Analysis of the cellular proliferation marker, Ki67, revealed that AZD0530 in combination with tamoxifen $\left(10^{-7} \mathrm{M}\right)$ significantly inhibited cellular proliferation in both MCF7 (A) and T47D (B) cells.

These events were seen from the earliest time point examined (1 week). Graphs are the mean of three experiments and show counts of Ki-67 stained cells (1,000 cells counted per treatment sample). Scale bar (shown in control sample) represents $20 \mu \mathrm{m} ;{ }^{*} P<0.02$ vs. tamoxifen alone
A

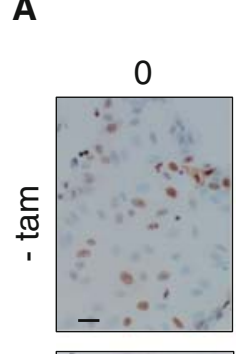

10 days
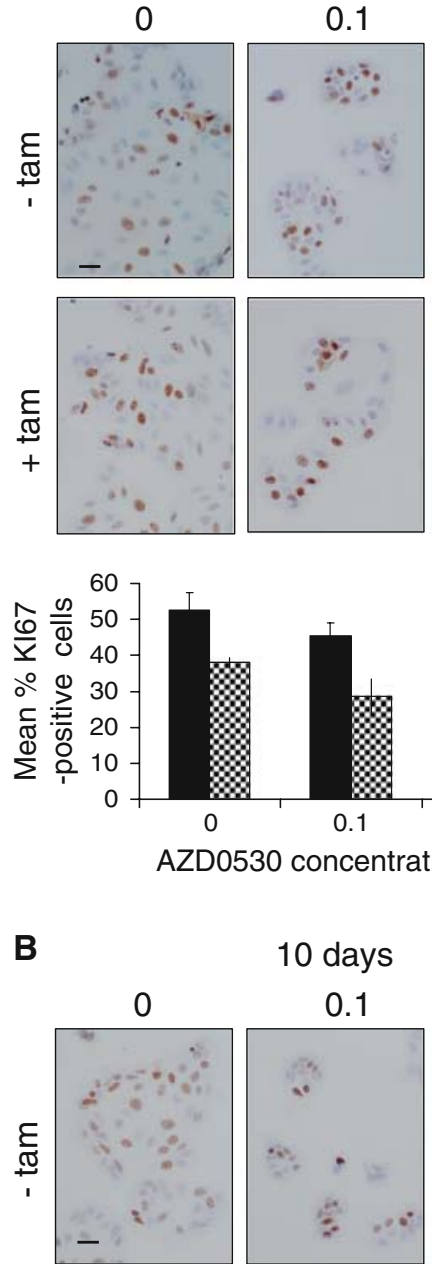

B

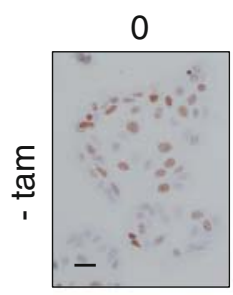

10 days

0.1
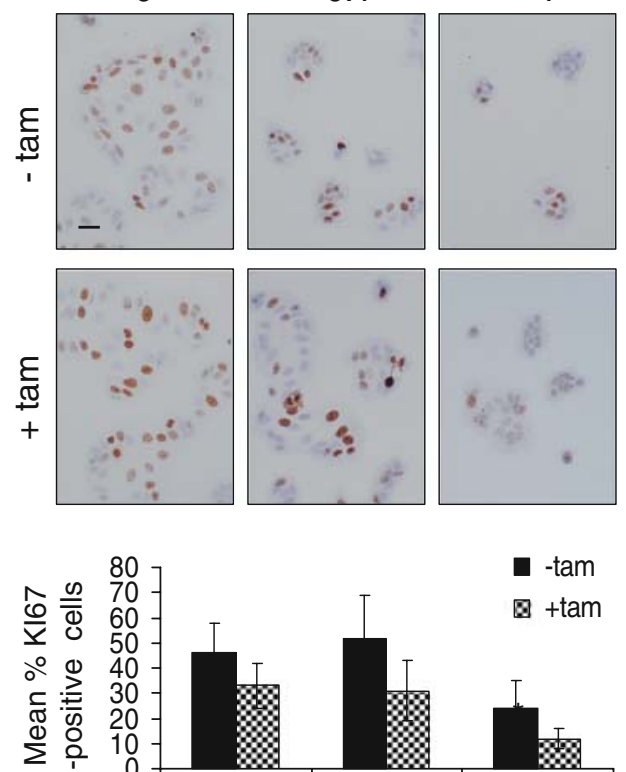

-tam

\$ +tam

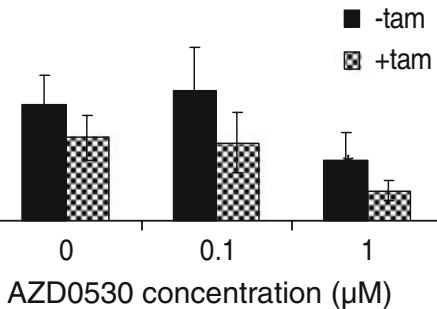

MCF7

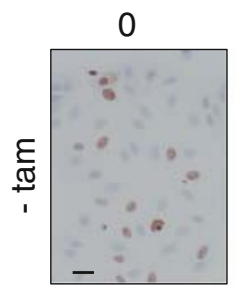

4 weeks
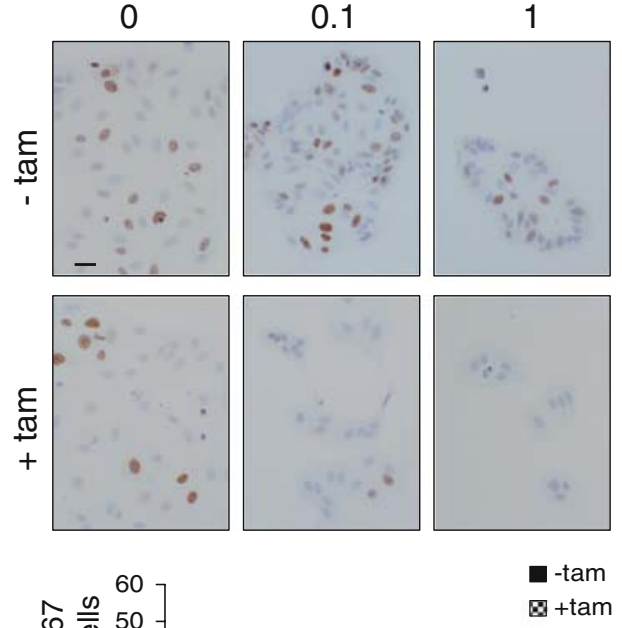

Qtam

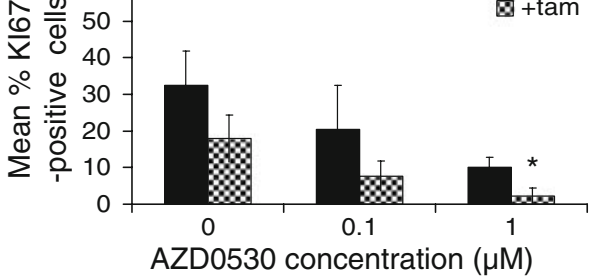

T47D

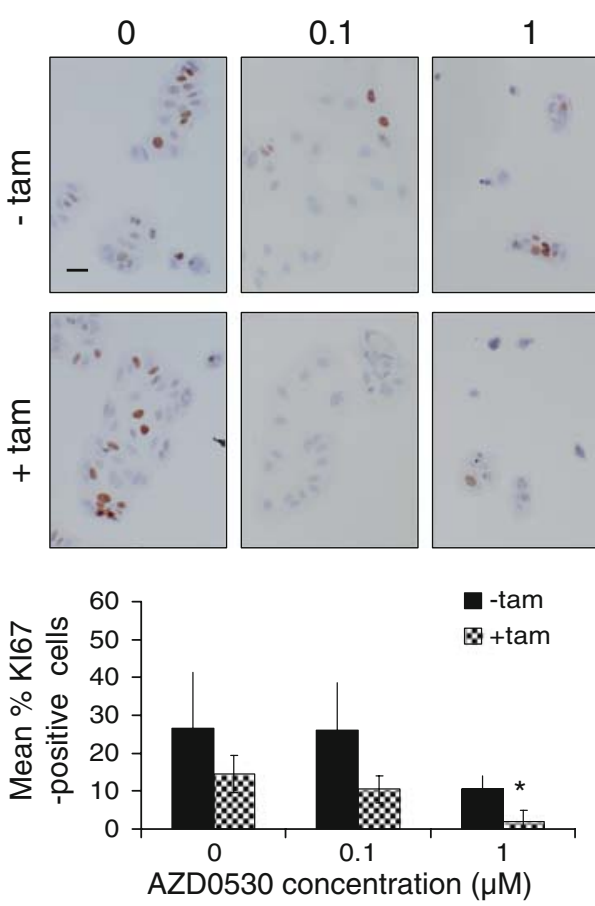

\section{Discussion}

Endocrine therapy is a major therapeutic option in the management of breast cancer. Tamoxifen is the most widely used anti-oestrogen, with approximately $50 \%$ of women having ER-positive breast disease benefiting from this treatment $[28,29]$. However, acquisition of resistance to such therapies frequently arises and, in such cases, the identification of novel targets that promote a resistant phenotype may themselves prove useful targets through which the development of resistance and the associated tumour re-growth and spread may be delayed or prevented. 
Table 2 RT-PCR analysis of proliferation-related gene expression was performed with subsequent densitometric analysis of PCR products

\begin{tabular}{|c|c|c|c|c|c|c|c|c|}
\hline & \multicolumn{4}{|l|}{ CyclinD1 } & \multicolumn{4}{|l|}{$\mathrm{c}-\mathrm{Myc}$} \\
\hline & AZD0530 & Wk1 & Wk4 & Wk8 & AZD0530 & Wk1 & Wk4 & Wk8 \\
\hline \multicolumn{9}{|l|}{ MCF7 } \\
\hline \multirow[t]{2}{*}{$-\operatorname{tam}$} & - & 1 & 1 & 1 & - & 1 & 1 & 1 \\
\hline & + & $0.87 \pm 0.03$ & $0.56 \pm 0.19$ & $0.68 \pm 0.19$ & + & $0.63 \pm 0.09$ & $0.49 \pm 0.27$ & $0.42 \pm 0.04$ \\
\hline \multirow[t]{2}{*}{$+\operatorname{tam}$} & - & $1.01 \pm 0.18$ & $0.78 \pm 0.02$ & $0.88 \pm 0.05$ & - & $1.21 \pm 0.15$ & $0.42 \pm 0.22$ & $0.79 \pm 0.01$ \\
\hline & + & $1.07 \pm 0.06$ & $0.41 \pm 0.05^{*}$ & $0.50 \pm 0.13^{*}$ & + & $0.50 \pm 0.14$ & $0.42 \pm 0.08$ & $0.21 \pm 0.12$ \\
\hline \multicolumn{9}{|l|}{ T47D } \\
\hline \multirow[t]{2}{*}{$-\operatorname{tam}$} & - & 1 & 1 & 1 & - & 1 & 1 & 1 \\
\hline & + & $0.80 \pm 0.18$ & $0.90 \pm 0.14$ & $0.69 \pm 0.16$ & + & $1.11 \pm 0.03$ & $075 \pm 0.23$ & $1.01 \pm 0.20$ \\
\hline \multirow[t]{2}{*}{$+\operatorname{tam}$} & - & $0.75 \pm 0.21$ & $1.03 \pm 0.07$ & $1.13 \pm 0.19$ & - & $0.46 \pm 0.18$ & $0.26 \pm 0.05$ & $0.52 \pm 0.04$ \\
\hline & + & $0.52 \pm 0.09 *$ & $0.77 \pm 0.39$ & $0.31 \pm 0.23 *$ & + & $0.70 \pm 0.34$ & $0.64 \pm 0.11$ & $0.24 \pm 0.12 *$ \\
\hline
\end{tabular}

Data was normalised to actin and calculated as mean expression ratio (vs. untreated control) \pm sd. These data revealed that dual inhibition of both Src and the ER significantly suppressed expression of c-myc and cyclin-D1 in both MCF7 and T47D cells compared to either treatment alone. Data is mean of three separate experiments. $* P<0.05$ for combination treatment vs. single agent
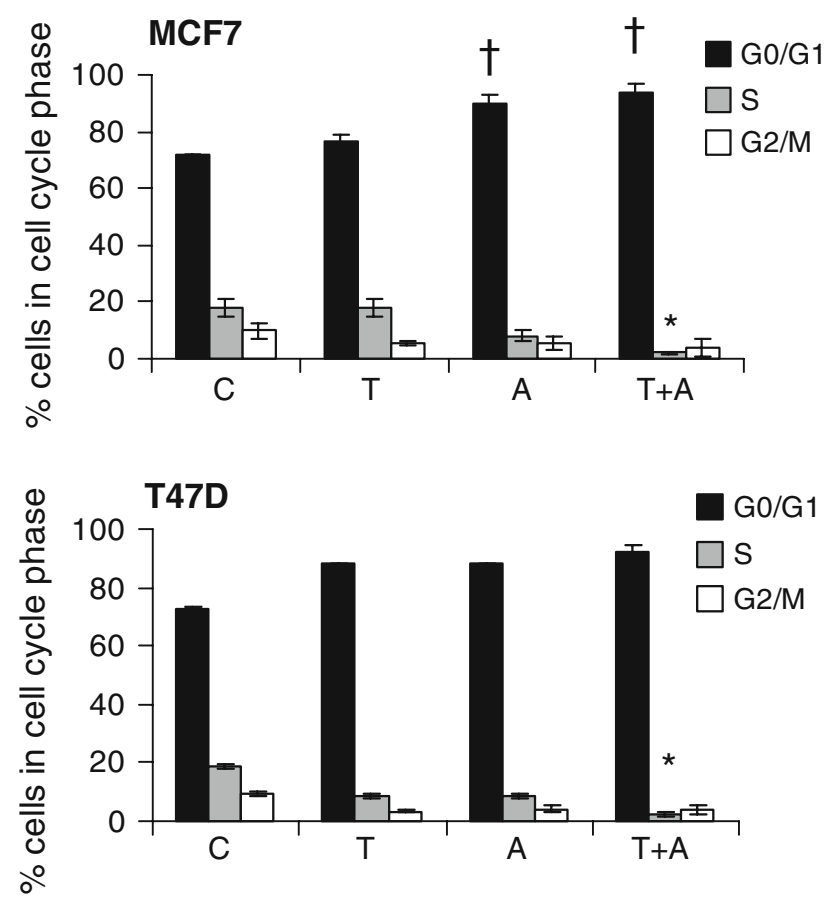

Fig. 4 Cells were maintained in culture in the presence of tamoxifen (' $\mathrm{T}$ ', $\left.10^{-7} \mathrm{M}\right)$, AZD0530 ('A', $1 \mu \mathrm{M}$ ) or the combination for 4 weeks. Cells were subsequently analysed for cell cycle phase using a flow cytometer. A significant reduction in cells in $\mathrm{S}$ phase was observed in cells cultured in the presence of tamoxifen plus AZD0530 combined. $* P<0.05$ vs. single agent treatment

We and others have recently identified a role for Src kinase in acquired endocrine resistance in vitro [11, 19], where it may regulate both proliferative and invasive responses in such cells. Data is emerging which reveals Src kinase as a novel tumour target, where its inhibition is effective at suppressing proliferation and/or metastatic events in a wide range of tumour types including CML
[30, 31], colon tumours [32, 33] and pancreatic cancer $[34,35]$. Further studies [36, 37] also provide compelling evidence that targeting Src may be of value in combination with existing chemotherapy to provide an augmented antitumour response. In breast cancer cells, Src is implicated as a key element in non-genomic, oestrogen-induced MAPK and MMP activation [16, 38, 39] and oestrogen-mediated cellular proliferation and cell-cycle progression [40, 41]. Interestingly, tamoxifen treatment itself has been reported to promote activation of intercellular signalling elements, including Src, resulting in cellular migration [42] and tamoxifen-mediated adhesion-dependent cell survival occurs through a Src-dependent process [43]. Thus, the ability to inhibit Src activity, alongside targeting of the ER with anti-oestrogens, may enhance the anti-tumour activity seen with each agent alone. Indeed, two recent studies provide compelling evidence to support such a hypothesis, demonstrating the short-term effectiveness of such combinational treatments in preventing the growth of MCF7 cells [25, 44]. However, it is currently unknown whether co-targeting both Src and the ER is effective in other ERpositive cell lines and whether such treatment regimens would be effective in circumventing the phenomena of acquired tamoxifen resistance that occurs following chronic exposure to this agent $[8,45,46]$.

Our data demonstrates that combining tamoxifen with the novel Src/Abl inhibitor, AZD0530 [20], improves the growth-inhibitory response seen with each treatment alone. Moreover, whereas long-term treatment with each agent alone resulted in the acquisition of a resistant state as demonstrated by a regain in growth ability in the presence of the drug, cells exposed to the combination of tamoxifen and AZD0530 did not acquire resistance; rather, complete cell loss was observed following such treatments in two 
Fig. 5 Cellular migration and invasion was assessed every two weeks during treatment (a). Dual inhibition of Src kinase and ER promoted a greater inhibition of these

characteristics than either agent alone, with the remaining few cells present at the longest time points having little or no intrinsic invasive or migratory capacity. (Data is presented as per-cent of control invasion at that time point, with the dotted line representing the control value $(=100 \%)$. (b) Western blot analysis of MCF7 and T47D cell samples following continuous exposure to the agents as indicated. Tamoxifen alone had only a modest inhibitory effect on the activity of Src kinase and the Src substrate, FAK, with levels of Src and FAK appearing to increase by week 10 (MCF7 cells) and week 12 (T47D cells). Inclusion of AZD0530 with tamoxifen almost completely inhibited activity of Src and FAK for the duration of the experiment. $\mathrm{t}=$ total protein; $\mathrm{p}=$ phospho protein (pY419 Src; pY861 FAK). Gels are representative of three separate experiments; accompanying graphs show densitometry data from all experiments, calculated as mean optical density of treated samples as a per-cent of control (untreated) cells normalized against $\beta$-actin
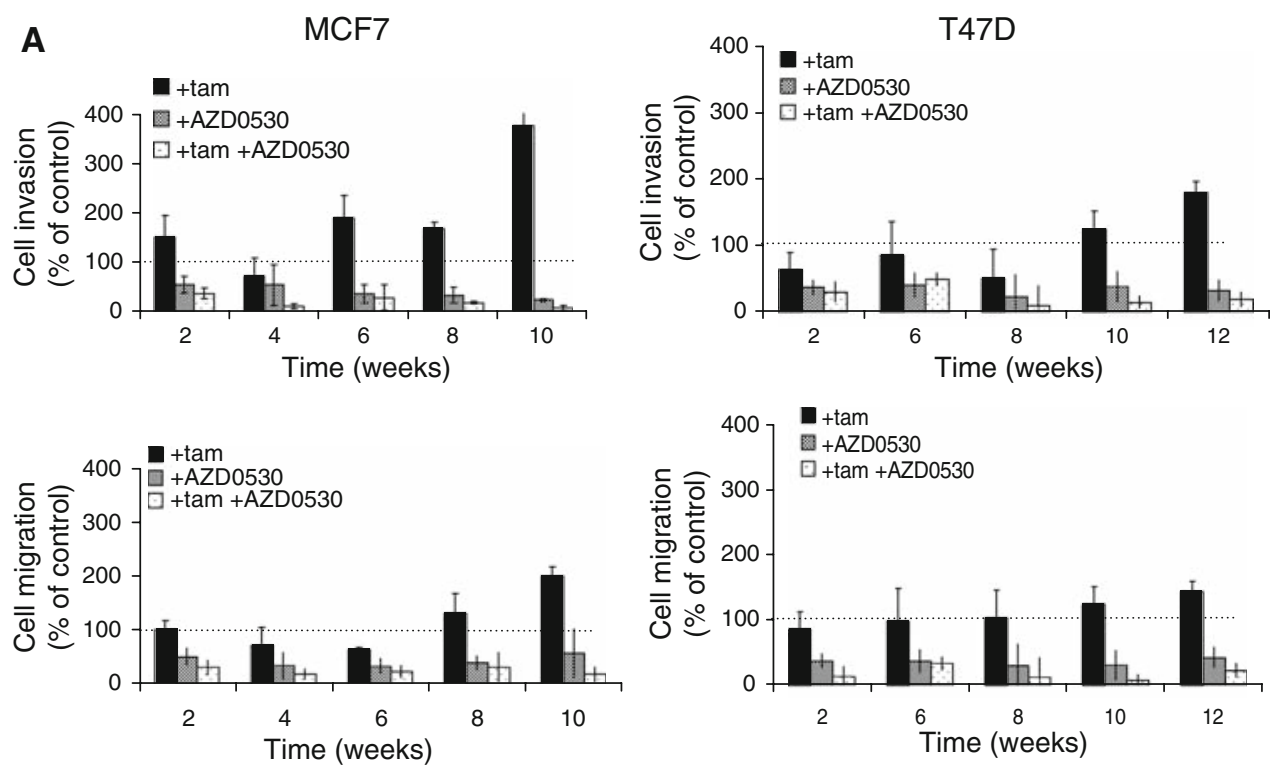

B
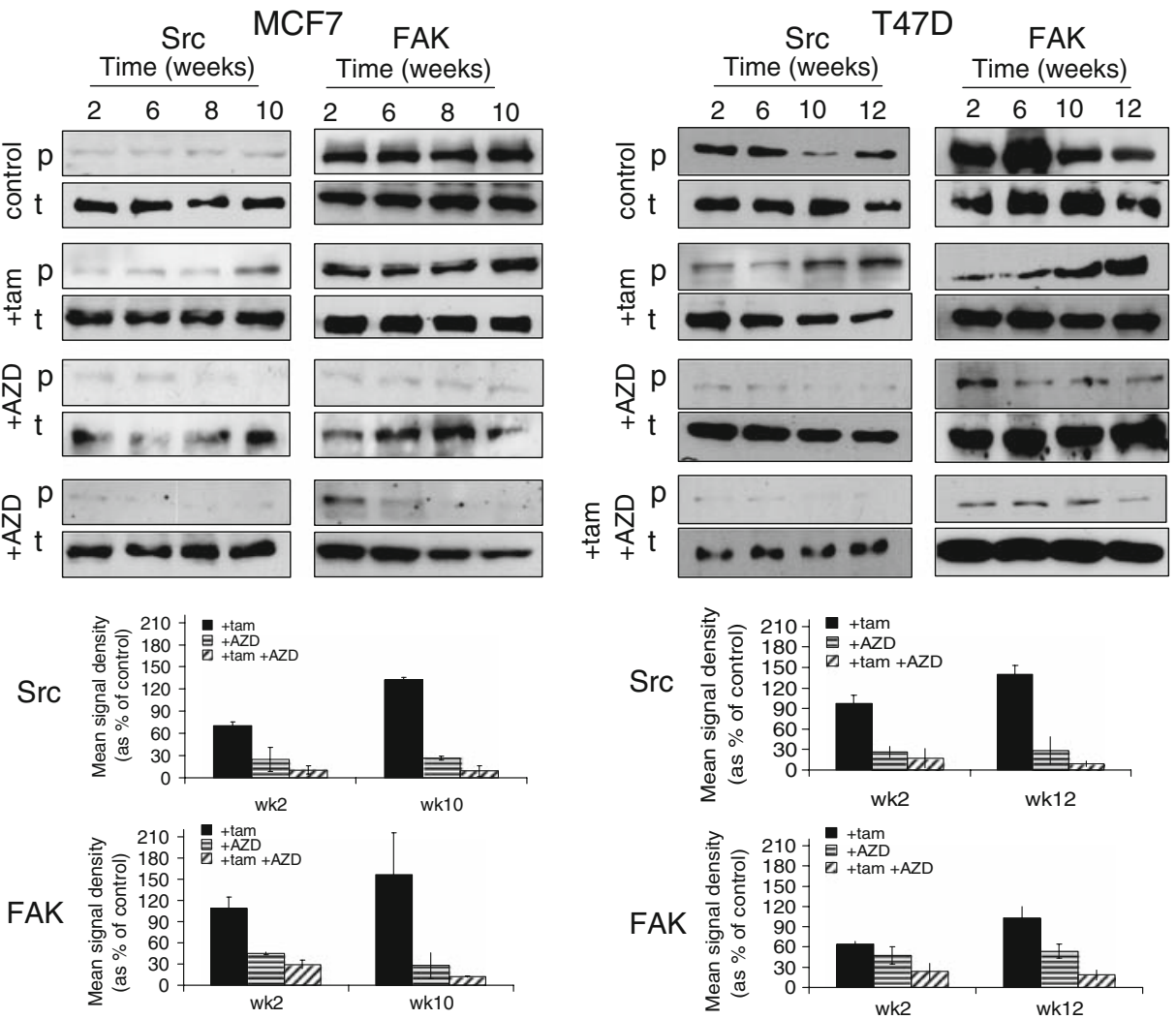

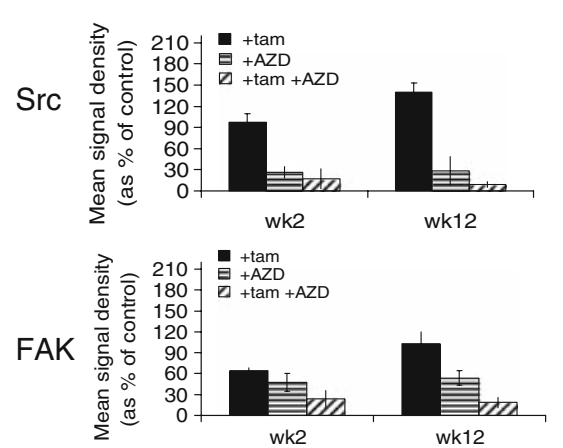

independent ER-positive cell lines (MCF7 and T47D). These data were achieved using clinically relevant concentrations of AZD0530 since data on the pharmacokinetics of AZD0530 suggest average plasma concentrations of $552 \mathrm{ng} / \mathrm{ml}$ [range $356-855 \mathrm{ng} / \mathrm{ml}$ ] are achievable in humans using a single daily dose regimen [47] and are thus comparable with the concentrations used in this study $(1 \mu \mathrm{M}=542 \mathrm{ng} / \mathrm{ml})$.
Although inhibition of Src activity has previously been demonstrated to induce apoptosis in cancer cells through a variety of mechanisms including down regulation of $\mathrm{Bcl}-2$ and $\mathrm{Bcl}-\mathrm{X}_{\mathrm{L}}$ expression [48], caspase activation [49] and decreased AKT phosphorylation [50], we did not observed a significant increase in apoptotic cells following dual targeting of Src and ER. That apoptosis does not present a mechanism of cell loss induced by combination treatment 
was also confirmed through investigating presence of poly(ADP-ribose) polymerase (PARP) cleavage products, indicative of caspase activation and apoptosis; no such cleavage of PARP was detectable in the lysates of such cells (S. Hiscox, unpublished observations).

Despite no evidence for a role of apoptosis, our data clearly demonstrates that combination treatment reduced the proliferative capacity of these cells, as revealed by a loss of expression of the Ki-67 cellular proliferation. Indeed, cell cultures treated with tamoxifen and AZD0530 combined were almost entirely Ki-67-negative after 4 weeks treatment. Although the ability of Src kinase inhibitors to suppress tumour cell growth are widely reported [51-53], cells treated with either tamoxifen or AZD0530 alone still had a significant number of Ki-67positive cells remaining at these time points. Our RT-PCR analysis suggests that these observations might be due to modulation of cyclin-D1 and c-myc, genes which play a central role in the control of cellular proliferation. Such data is not surprising given the reported interplay between Src and cell-cycle-associated genes [54, 55]; indeed, it has been recently reported that pharmacological inhibition of Src activity in MCF7 cells results in suppression of both cMyc and cyclinD1 [19]. Our data here demonstrates that prolonged exposure to a Src inhibitor and tamoxifen results in even greater suppression of these elements and interestingly, cell cycle analysis revealed a significant reduction in the numbers of cells in $\mathrm{S}$ phase following combination treatment. Given that Ki67 positivity is significantly correlated with cells in $S$ phase $[56,57]$, these cell cycle observations confirm our Ki67 data and together these observations demonstrate that combined targeting of the ER and Src in ER-positive MCF7 and T47D cells results in a loss of proliferative response.

A significant impact of combining Src inhibition with tamoxifen was the ability to suppress the migratory and invasive characteristics of these cells. MCF7 cells are poorly invasive in vitro, whereas T47D cells have a higher intrinsic invasive capacity. However, despite these differences, the capacity of both cell types to migrate and invade in the absence of any exogenous stimulation in vitro is significantly enhanced following the long-term treatment with antihormones and the acquisition of an endocrineresistant state [11] and Fig. 5a). Interestingly, T47D models of acquired resistance appeared generally less invasive than did MCF7 cells that were tamoxifen resistant. The acquisition of endocrine resistance is accompanied by altered expression and/or activation of growth factor signalling pathways (reviewed in [58]. However, it is likely that models of acquired resistance derived from different breast cancer cell lines (e.g. MCF7, T47D) will differ in the intrinsic expression of growth factor receptors/pathway components; i.e. the dominant signalling pathway in one model may not be the same for another. This can give rise to phenotypic differences between drug-resistant cells that may include their proliferative and invasive capacities. The observations that acquired resistance in vitro is accompanied by an enhanced invasive behaviour may have significant implications in vivo, where the development of aggressive characteristics, even in the absence of cellular proliferation, may favour cell dissemination and tumour spread. Interestingly, we observed that resistance was also acquired to AZD0530 monotherapy upon continued exposure, as was the case with tamoxifen. However, unlike tamoxifen resistant cells, AZD0530 resistant cells had only a modest invasive capacity further implicating Src activity as a key element in the acquisition of an aggressive cell phenotype. Despite Src activity remaining suppressed in AZD0530-resistant cells, little is known concerning the activity of other Src family kinases in such cells. Although AZD0530 is known to inhibit the Src family kinase Yes [20], it remains to be determined whether there is a role for other members of the Src family in AZD0530-resistant cells and their contribution to their proliferative capacity.

Our data shows that the effect of combining AZD0530 and tamoxifen was to produce cells which were unable to migrate or invade in our in vitro assays. We and others have previously demonstrated that Src kinase promotes cellular invasion through a mechanism involving activation of FAK [11, 19, 59]. Importantly, dual treatment of both MCF7 and T47D cells, in addition to suppressing Src activity, also consistently suppressed the activity of the Src-associated molecule FAK a central component of the cells' migratory machinery. Such data may further reflect the potential benefit of combination drug regimens that involve Src inhibitors in suppressing characteristics of tumour behaviour involved in tumour spread.

In summary, these data suggest that integration of Src kinase inhibitors with current anti-oestrogen therapies may present a useful treatment regimen through which subsequent anti-oestrogen resistance development could be prevented.

Acknowledgments The authors wish to thank Carol Dutkowski, Denise Barrow, Lindy Goddard, Huw Mottram and Lucy Green for their expert contributions to this work.

\section{References}

1. Clarke M, Collins R, Darby S, Davies C, Elphinstone P, Evans E et al (2005) Effects of radiotherapy and of differences in the extent of surgery for early breast cancer on local recurrence and 15-year survival: an overview of the randomised trials. Lancet 366:2087-2106

2. Nicholson RI, Hutcheson IR, Britton D, Knowlden JM, Jones HE, Harper ME et al (2005) Growth factor signalling networks in breast cancer and resistance to endocrine agents: new therapeutic 
strategies. J Steroid Biochem Mol Biol 93:257-262. doi: 10.1016/j.jsbmb.2004.12.006

3. Clarke R, Skaar TC, Bouker KB, Davis N, Lee YR, Welch JN et al (2001) Molecular and pharmacological aspects of antiestrogen resistance. J Steroid Biochem Mol Biol 76:71-84. doi: 10.1016/S0960-0760(00)00193-X

4. Clarke R, Liu MC, Bouker KB, Gu Z, Lee RY, Zhu Y et al (2003) Antiestrogen resistance in breast cancer and the role of estrogen receptor signaling. Oncogene 22:7316-7339. doi:10.1038/sj.onc. 1206937

5. Jordan VC (1995) Third annual William L. McGuire Memorial Lecture. "Studies on the estrogen receptor in breast cancer"-20 years as a target for the treatment and prevention of cancer. Breast Cancer Res Treat 36:267-285. doi:10.1007/BF00713399

6. Nicholson RI, Gee JM, Knowlden J, McClelland R, Madden TA, Barrow D et al (2003) The biology of antihormone failure in breast cancer. Breast Cancer Res Treat 80(Suppl 1):S29-S34. discussion S35. doi:10.1023/A:1025467500433

7. Nicolini A, Giardino R, Carpi A, Ferrari P, Anselmi L, Colosimo $\mathrm{S}$ et al (2006) Metastatic breast cancer: an updating. Biomed Pharmacother 60:548-556. doi:10.1016/j.biopha.2006.07.086

8. Knowlden JM, Hutcheson IR, Jones HE, Madden T, Gee JM, Harper ME et al (2003) Elevated levels of epidermal growth factor receptor/c-erbB2 heterodimers mediate an autocrine growth regulatory pathway in tamoxifen-resistant MCF-7 cells. Endocrinology 144:1032-1044. doi:10.1210/en.2002-220620

9. Lykkesfeldt AE, Madsen MW, Briand P (1994) Altered expression of estrogen-regulated genes in a tamoxifen-resistant and ICI 164, 384 and ICI 182, 780 sensitive human breast cancer cell line, MCF-7/TAMR-1. Cancer Res 54:1587-1595

10. Hiscox S, Morgan L, Barrow D, Dutkowskil C, Wakeling A, Nicholson RI (2004) Tamoxifen resistance in breast cancer cells is accompanied by an enhanced motile and invasive phenotype: inhibition by gefitinib ('Iressa', ZD1839). Clin Exp Metastasis 21:201-212. doi:10.1023/B:CLIN.0000037697.76011.1d

11. Hiscox S, Morgan L, Green TP, Barrow D, Gee J, Nicholson RI (2006) Elevated Src activity promotes cellular invasion and motility in tamoxifen resistant breast cancer cells. Breast Cancer Res Treat 97:263-274. doi:10.1007/s10549-005-9120-9

12. Alvarez RH, Kantarjian HM, Cortes JE (2006) The role of Src in solid and hematologic malignancies: development of new-generation Src inhibitors. Cancer 107:1918-1929. doi:10.1002/cncr. 22215

13. Yeatman TJ (2004) A renaissance for SRC. Nat Rev Cancer 4:470-480. doi:10.1038/nrc1366

14. Rucci N, Recchia I, Angelucci A, Alamanou M, Del Fattore A, Fortunati D et al (2006) Inhibition of protein kinase c-Src reduces the incidence of breast cancer metastases and increases survival in mice: implications for therapy. $J$ Pharmacol Exp Ther 318:161-172. doi:10.1124/jpet.106.102004

15. Wilson GR, Cramer A, Welman A, Knox F, Swindell R, Kawakatsu $\mathrm{H}$ et al (2006) Activated c-SRC in ductal carcinoma in situ correlates with high tumour grade, high proliferation and HER2 positivity. Br J Cancer 95:1410-1414. doi:10.1038/sj.bjc.6603444

16. Razandi M, Pedram A, Park ST, Levin ER (2003) Proximal events in signaling by plasma membrane estrogen receptors. J Biol Chem 278:2701-2712. doi:10.1074/jbc.M205692200

17. Coleman KM, Smith CL (2001) Intracellular signaling pathways: nongenomic actions of estrogens and ligand-independent activation of estrogen receptors. Front Biosci 6:D1379-D1391. doi: 10.2741/Coleman

18. Riggins RB, Thomas KS, Ta HQ, Wen J, Davis RJ, Schuh NR et al (2006) Physical and functional interactions between Cas and c-Src induce tamoxifen resistance of breast cancer cells through pathways involving epidermal growth factor receptor and signal transducer and activator of transcription 5b. Cancer Res 66:70077015. doi:10.1158/0008-5472.CAN-05-3952

19. Planas-Silva MD, Bruggeman RD, Grenko RT, Stanley Smith J (2006) Role of c-Src and focal adhesion kinase in progression and metastasis of estrogen receptor-positive breast cancer. Biochem Biophys Res Commun 341:73-81. doi:10.1016/j.bbrc.2005.12.164

20. Hennequin LF, Allen J, Breed J, Curwen J, Fennell M, Green $\mathrm{TP}$ et al (2006) N-(5-chloro-1, 3-benzodioxol-4-yl)-7-[2-(4methylpiperazin-1-yl) ethoxy]-5-(tetrahydro-2H-pyran-4-yloxy) quinazolin-4-amine, a novel, highly selective, orally available, dual-specific c-Src/Abl kinase inhibitor. J Med Chem 49:64656488. doi:10.1021/jm060434q

21. Serrels A, Macpherson IR, Evans TR, Lee YF, Clark EA, Sansom $\mathrm{OJ}$ et al (2006) Identification of potential biomarkers for measuring inhibition of Src kinase activity in colon cancer cells following treatment with dasatinib. Mol Cancer Ther 5:30143022. doi:10.1158/1535-7163.MCT-06-0382

22. Earley S, Plopper GE (2008) Phosphorylation of focal adhesion kinase promotes extravasation of breast cancer cells. Biochem Biophys Res Commun 366:476-482. doi:10.1016/j.bbrc.2007.11. 181

23. Vadlamudi RK, Sahin AA, Adam L, Wang RA, Kumar R (2003) Heregulin and HER2 signaling selectively activates c-Src phosphorylation at tyrosine 215. FEBS Lett 543:76-80. doi: 10.1016/S0014-5793(03)00404-6

24. Al-Dhaheri MH, Shah YM, Basrur V, Pind S, Rowan BG (2006) Identification of novel proteins induced by estradiol, 4-hydroxytamoxifen and acolbifene in T47D breast cancer cells. Steroids 71:966-978. doi:10.1016/j.steroids.2006.07.006

25. Planas-Silva MD, Hamilton KN (2007) Targeting c-Src kinase enhances tamoxifen's inhibitory effect on cell growth by modulating expression of cell cycle and survival proteins. Cancer Chemother Pharmacol 60:535-543. doi:10.1007/s00280-006-0398-z

26. Adhikary S, Eilers M (2005) Transcriptional regulation and transformation by Myc proteins. Nat Rev Mol Cell Biol 6:635645. doi:10.1038/nrm1703

27. Cox BD, Natarajan M, Stettner MR, Gladson CL (2006) New concepts regarding focal adhesion kinase promotion of cell migration and proliferation. J Cell Biochem 99:35-52. doi: $10.1002 /$ jcb. 20956

28. Howell SJ, Johnston SR, Howell A (2004) The use of selective estrogen receptor modulators and selective estrogen receptor down-regulators in breast cancer. Best Pract Res Clin Endocrinol Metab 18:47-66. doi:10.1016/j.beem.2003.08.002

29. Ring A, Dowsett M (2004) Mechanisms of tamoxifen resistance. Endocr Relat Cancer 11:643-658. doi:10.1677/erc.1.00776

30. Golas JM, Arndt K, Etienne C, Lucas J, Nardin D, Gibbons J et al (2003) SKI-606, a 4-anilino-3-quinolinecarbonitrile dual inhibitor of $\mathrm{Src}$ and $\mathrm{Abl}$ kinases, is a potent antiproliferative agent against chronic myelogenous leukemia cells in culture and causes regression of K562 xenografts in nude mice. Cancer Res 63:375381

31. Tipping AJ, Baluch S, Barnes DJ, Veach DR, Clarkson BM, Bornmann WG et al (2004) Efficacy of dual-specific Bcr-Abl and Src-family kinase inhibitors in cells sensitive and resistant to imatinib mesylate. Leukemia 18:1352-1356. doi:10.1038/sj.leu. 2403416

32. Golas JM, Lucas J, Etienne C, Golas J, Discafani C, Sridharan L et al (2005) SKI-606, a Src/Abl inhibitor with in vivo activity in colon tumor xenograft models. Cancer Res 65:5358-5364. doi: 10.1158/0008-5472.CAN-04-2484

33. Nam JS, Ino Y, Sakamoto M, Hirohashi S (2002) Src family kinase inhibitor PP2 restores the E-cadherin/catenin cell adhesion system in human cancer cells and reduces cancer metastasis. Clin Cancer Res 8:2430-2436 
34. Duxbury MS, Ito H, Zinner MJ, Ashley SW, Whang EE (2004) Inhibition of SRC tyrosine kinase impairs inherent and acquired gemcitabine resistance in human pancreatic adenocarcinoma cells. Clin Cancer Res 10:2307-2318. doi:10.1158/1078-0432. CCR-1183-3

35. Yezhelyev MV, Koehl G, Guba M, Brabletz T, Jauch KW, Ryan A et al (2004) Inhibition of SRC tyrosine kinase as treatment for human pancreatic cancer growing orthotopically in nude mice. Clin Cancer Res 10:8028-8036. doi:10.1158/1078-0432.CCR04-0621

36. Fiskus W, Pranpat M, Balasis M, Bali P, Estrella V, Kumaraswamy $S$ et al (2006) Cotreatment with vorinostat (suberoylanilide hydroxamic acid) enhances activity of dasatinib (BMS-354825) against imatinib mesylate-sensitive or imatinib mesylate-resistant chronic myelogenous leukemia cells. Clin Cancer Res 12:58695878. doi:10.1158/1078-0432.CCR-06-0980

37. Pengetnze Y, Steed M, Roby KF, Terranova PF, Taylor CC (2003) Src tyrosine kinase promotes survival and resistance to chemotherapeutics in a mouse ovarian cancer cell line. Biochem Biophys Res Commun 309:377-383. doi:10.1016/j.bbrc.2003.08.012

38. Belcher SM, Le HH, Spurling L, Wong JK (2005) Rapid estrogenic regulation of extracellular signal- regulated kinase $1 / 2$ signaling in cerebellar granule cells involves a $\mathrm{G}$ protein- and protein kinase A-dependent mechanism and intracellular activation of protein phosphatase 2A. Endocrinology 146:5397-5406. doi:10.1210/en.2005-0564

39. Filardo EJ, Quinn JA, Frackelton AR Jr, Bland KI (2002) Estrogen action via the $G$ protein-coupled receptor, GPR30: stimulation of adenylyl cyclase and cAMP-mediated attenuation of the epidermal growth factor receptor-to-MAPK signaling axis. Mol Endocrinol 16:70-84. doi:10.1210/me.16.1.70

40. Castoria G, Migliaccio A, Bilancio A, Di Domenico M, de Falco A, Lombardi $\mathrm{M}$ et al (2001) PI3-kinase in concert with Src promotes the S-phase entry of oestradiol-stimulated MCF-7 cells. EMBO J 20:6050-6059. doi:10.1093/emboj/20.21.6050

41. Song RX, Zhang Z, Santen RJ (2005) Estrogen rapid action via protein complex formation involving ERalpha and Src. Trends Endocrinol Metab 16:347-353. doi:10.1016/j.tem.2005.06.010

42. Acconcia F, Barnes CJ, Kumar R (2006) Estrogen and tamoxifen induce cytoskeletal remodeling and migration in endometrial cancer cells. Endocrinology 147:1203-1212. doi:10.1210/en.2005-1293

43. Cowell LN, Graham JD, Bouton AH, Clarke CL, O'Neill GM (2006) Tamoxifen treatment promotes phosphorylation of the adhesion molecules, p130Cas/BCAR1, FAK and Src, via an adhesion-dependent pathway. Oncogene 25:7597-7607. doi: 10.1038/sj.onc. 1209747

44. Herynk MH, Beyer AR, Cui Y, Weiss H, Anderson E, Green TP et al (2006) Cooperative action of tamoxifen and c-Src inhibition in preventing the growth of estrogen receptor-positive human breast cancer cells. Mol Cancer Ther 5:3023-3031. doi: 10.1158/1535-7163.MCT-06-0394

45. Badia E, Duchesne MJ, Semlali A, Fuentes M, Giamarchi C, Richard-Foy $\mathrm{H}$ et al (2000) Long-term hydroxytamoxifen treatment of an MCF-7-derived breast cancer cell line irreversibly inhibits the expression of estrogenic genes through chromatin remodeling. Cancer Res 60:4130-4138

46. Park WC, Liu H, Macgregor Schafer J, Jordan VC (2005) Deregulation of estrogen induced telomerase activity in tamoxifen-resistant breast cancer cells. Int J Oncol 27:1459-1466

47. Gallagher NJ, Lockton AJ, Macpherson M, Marshall A, Clack G (2005) A phase I multiple ascending dose study to assess the safety, tolerability and pharmacokinetics of AZD0530, a highly selective, orally available, dual-specific Src-Abl kinase inhibitor. Proc Am Assoc Cancer Res 46:3792

48. Fujimoto E, Sato H, Nagashima Y, Negishi E, Shirai S, Fukumoto K et al (2005) A Src family inhibitor (PP1) potentiates tumor-suppressive effect of connexin 32 gene in renal cancer cells. Life Sci 76:2711-2720. doi:10.1016/j.lfs.2004.10.049

49. Lee M, Kim JY, Koh WS (2004) Apoptotic effect of PP2 a Src tyrosine kinase inhibitor, in murine B cell leukemia. J Cell Biochem 93:629-638. doi:10.1002/jcb.20215

50. Liu Z, Falola J, Zhu X, Gu Y, Kim LT, Sarosi GA et al (2004) Antiproliferative effects of Src inhibition on medullary thyroid cancer. J Clin Endocrinol Metab 89:3503-3509. doi: 10.1210/jc.2003-031917

51. Mizenina OA, Moasser MM (2004) S-phase inhibition of cell cycle progression by a novel class of pyridopyrimidine tyrosine kinase inhibitors. Cell Cycle 3:796-803

52. Moasser MM, Srethapakdi M, Sachar KS, Kraker AJ, Rosen N (1999) Inhibition of Src kinases by a selective tyrosine kinase inhibitor causes mitotic arrest. Cancer Res 59:6145-6152

53. Wisniewski D, Lambek CL, Liu C, Strife A, Veach DR, Nagar B et al (2002) Characterization of potent inhibitors of the Bcr-Abl and the c-kit receptor tyrosine kinases. Cancer Res 62:4244-4255

54. Frame MC (2002) Src in cancer: deregulation and consequences for cell behaviour. Biochim Biophys Acta 1602:114-130

55. Riley D, Carragher NO, Frame MC, Wyke JA (2001) The mechanism of cell cycle regulation by v-Src. Oncogene 20:59415950. doi:10.1038/sj.onc. 1204826

56. Martinez-Arribas F, Nunez MJ, Piqueras V, Lucas AR, Sanchez J, Tejerina A et al (2002) Flow cytometry vs. Ki67 labelling index in breast cancer: a prospective evaluation of 181 cases. Anticancer Res 22:295-298

57. Turner HE, Wass JA (1999) Are markers of proliferation valuable in the histological assessment of pituitary tumours? Pituitary 1:147-151. doi:10.1023/A:1009979128608

58. Nicholson RI, Hutcheson IR, Jones HE, Hiscox SE, Giles M, Taylor KM et al (2007) Growth factor signalling in endocrine and anti-growth factor resistant breast cancer. Rev Endocr Metab Disord 8:241-253. doi:10.1007/s11154-007-9033-5

59. Brunton VG, Avizienyte E, Fincham VJ, Serrels B, Metcalf CA 3rd, Sawyer TK et al (2005) Identification of Src-specific phosphorylation site on focal adhesion kinase: dissection of the role of Src SH2 and catalytic functions and their consequences for tumor cell behavior. Cancer Res 65:1335-1342. doi:10.1158/00085472.CAN-04-1949 